\title{
Embracing Technology and the Challenges of Complexity ${ }^{1}$
}

\author{
Alice Robbin \\ School of Library \& Information Science Indiana University Bloomington \\ arobbin@indiana.cedu
}

\begin{abstract}
Advances in new digital platforms, innovative applications, and the convergence of computer, information, and communication technologies are transforming our everyday lives. ICTs have consequences for governance, community, work, information, knowledge, human communication, and well being, to name only a few. We live in a world where change is a constant, where interdependencies are multiple, heterogeneous, and increasingly fragile, and where uncertainty, ambiguity, incomplete information, and unanticipated consequences are the norm. The outcomes of our engagement with technology are complex and unpredictable. They defy simple conclusions because they are historical, temporal, situational, and embedded. Moreover, they are problematic and surprising: inconsistent, paradoxical, disorderly, contradictory, and contingent. In this talk I want to examine some of the empirical evidence about the complexity of our technological landscape and suggest ways to make sense of what is happening through theoretical frameworks drawn from different disciplinary traditions. Following Nobel Laureate in Economics Elinor Ostrom, our aim should be to "dissect and harness complexity rather than eliminate it" so that we can create responsive and resilient systems.
\end{abstract}

Keywords: information and communication technologies (ICTs), social informatics, theory, methodology, empirical evidence, complexity

\section{Introduction}

I am honored to be invited to give this keynote address at our 2010 IADIS Conference on ICT, Society and Human Beings and thank the organizers for this invitation. To anticipate my remarks, it is fundamentally a call to expand our research agenda for the future: to new, or more precisely to taken-for-granted, theoretical frameworks; to the application of a variety of methodologies; and to an expanded basis for empirical evidence. I do not provide much detail about these aspects of our scholarly endeavors but rather highlight the contribution of five individuals whose work provides us with guidance about useful theoretical frameworks and concepts derived from these frameworks.

I have organized my remarks in four parts. First, I offer a (perhaps) provocative critique of the dominant theoretical frameworks that we have relied on to study ICTs. Except for a few intrepid souls, we do not appear to be generating new ideas or conceptions of how to inform ourselves about the new technologies. But then, in the remaining remarks, I suggest a "way out". I suggest that we supplement our current thinking about new technologies and systematically incorporate other perspectives and theoretical frameworks. We also need to apply different empirical approaches as a foundation for our work. I suggest a broader range of theoretical possibilities, ones that received far less explicit attention, although they are nowhere "new", have been an implicit foundation for some of the scholarly work, and are stimulating and worthy of reflection. I direct attention to the theoretical foundations of the work of five scholars: Christian Fuchs and Wolfgang Hofkirchner of Austria (systems and complexity thinking); Gunilla Bradley of Sweden (convergence theory); and Elinor Ostrom (coupled social and ecological systems) and Bruce Bimber (reframed collective action theory) of the United States and their respective colleagues. I conclude with some remarks about my own intellectual trajectory and two examples of catastrophic events, the Haiti earthquake and the oil spill in the Gulf of Mexico, that encouraged me to formulate my remarks as I have done: why we must expand the theoretical foundations of our thinking about ICTs and society.

\footnotetext{
${ }^{1}$ This is both a slightly abridged version of the keynote address that I presented at the 2010 IADIS Conference on ICT, Society and Human Beings held July 28-30, 2010 in Freiburg, Germany; and an elaboration of the original text on the influence of Robert Alford that was suggested by an anonymous reviewer. Of course, I alone am responsible for the remarks I express in this address.
} 
Finally, I reflect on how these five scholars are exemplars of a collective commitment to interdisciplinary research and scholarship and urge that we assume this commitment as well.

\section{A Critique}

We have embraced information and communication technologies. They are, indeed, central to what this annual conference is about. For more than several decades, indeed if we study history, for centuries, accounts of new technologies have posited them as significant positive and negative forces. $^{2}$

We have generally referred to this accounting as "technological determinism." Bimber (1990) points out correctly that this concept is "somewhat elusive" and that is "used to describe what is really a variety of distinct views about the relationship of technological enterprise to other aspects of human activity" that "may employ different theoretical assumptions and explanatory approaches which are often not made explicit" (p. 333). He concludes that the term technological determinism is "poorly conceptualized" (p. 334). Bimber proposes that there are three different meanings about the significance of technology to social change: a "norm-based account", whereby social control over technology is relinquished and technology is autonomous; a "logical sequence account", whereby technology exercises causal influence on social practice; and an "unintended consequences account", whereby outcomes are uncertain and uncontrollable (which it may be argued is not "determinism" at all).

All three conceptions of technological determinism have played a major role in theorizing the relationship between new technologies and human activity. They are the basis for assumptions that govern the empirical research that fills the journal literature in new media studies, communication, information systems, information science, information technology, Internet studies, and the information society.

Dominant among social theorists in recent decades has been the theoretical perspective of the "social construction of technology" or the "social shaping of technology", which locates technology not as an objective material entity or tools or objects that can be analyzed separately, but one that acknowledges its relationship to culture, society, political processes, and institutions (see Mackenzie \& Wajcman, 1999; Bijker \& Law, 1992). ${ }^{3}$

Many social theorists have invoked various constructs to describe the nature of this relationship between the social and the technological/technical: "mutual shaping", "social shaping", "coconstitution", and a "co-evolution." Kling (2001, 200b; Kling et al., 2000), for example, analytically extended the concept of "social shaping" with the characterization of ICTs as socio-technical interaction networks. ICTs are not only socially shaped but in practice also highly intertwined with social relations and resources: "they co-constitute each other", Kling (2000b, p. 248) wrote. Social relationships are inscribed into technologies in ways that govern their access and forms of use, whereas the technologies themselves help shape the social relations and activities that unfold around them. Technologies and users must be analyzed integrally and with an emphasis on emergence, contingency, and co-evolution.

Outcomes of the use of any particular ICT are not, however, foretold by its properties. Affordances and constraints built into technology may limit or enable a range of actions. As such, outcomes of technology use are not fully (if at all) predictable based on either its affordances or the intentions of its creators and users. Effects of new technologies are "unique and wide-ranging and arise from the manner in which people appropriate them initially to substitute for and accomplish previously established communication practices" (Bimber et al., 2005, p. 384). "Actors adopt, employ, and transform technologies for a variety of reasons and to a wide range of effect" (Flanagin et

\footnotetext{
${ }^{2}$ Some of this introduction is drawn from Robbin et al. (2004).

${ }^{3}$ Some might argue that the dominant theoretical perspective of the social construction of technology is "reductionist", as Fuchs et al. (2001/2007, p. 8) do. "Constructivism can be seen as a reductionist conception that does not consider the dialectical relationship of the individual/consciousness and society/being. It does not take into account the limitation and structuration of individual action, and the thinking in social relationships." I take up the issue of "dialectic" later in my remarks.
} 
al., 2006, pp. 32-33; Bimber, 1994). This, decades of published empirical research has shown to be true. Nonetheless, various authors have contended that general tendencies guide outcomes of ICT use, such as the overall reinforcement of the distribution of power and resources (see Danziger et al., 1982; Fuchs, 2009) or the amplification of existing social and institutional trends when mediated by ICTs (Agre, 2002; Bimber, 1998, 1999, 2000, 2001; Norris, 2002).

Still, it seems to me that our visions remain over-determined and much analysis appears to posit a causal direction that is linear and unidirectional. Our hopes and dreams are bound up in technology. We "award these new technologies for their transformative ability" and for contributing to our productivity (Sturken \& Thomas, 2004, p. 3). We assign them autonomous authority and force (Wimmer, 2004). We believe that the new technologies are a powerful instrument for progress, social change, and redemption. "Technological development is", as Sturken and Thomas point out,

one of the primary sites through which we can chart the desires and concerns of a given social context and the preoccupations of particular moments in history. The meanings that are attributed to new technologies are some of the most important evidence we can find of the visions, both optimistic and anxious, through which modern societies cohere [...] visions [that are - A.R.] life-transforming, in both transcendent and threatening ways. (Sturken \& Thomas, 2004, pp. 1-2)

Fuchs (2003a) writes that "the new technologies are embedded in an antagonism..., they foster both positive opportunities and negative risks" (p. 158). At the same time that we draw inspiration from the potentiality of new technologies, we register concern, indeed anxiety, and even a cautionary approach, about the risks, effects, and consequences of technological innovation, which is reinforced by the narratives about technology that we read in daily news media coverage (see Weaver et al., 2009). Daily, the media report new developments and optimistic and pessimistic views of the future of technological innovation.

The topics are many. ${ }^{4}$ For changing the way the brain functions and for altering our attention. For information and media overload. For altering traditional as well as creating new "ties that bind", those associative and civic relations of affiliation, between parent and child, between children and adults, between friends, and between neighbors in a community. For creating new organizational forms for collective action. For liberty of expression and for surveillance. For blurring the boundaries between the public and private spheres. For altering traditional relations between citizen and the state, between nation states, between consumer and corporation, between citizen and corporation, between corporations, between corporation and the state, and between employer and employee. For creating a new information regime. For reducing or reinforcing social and economic inequality.

Over the last few years, however, I have begun to wonder about the progress we are making. We have now accumulated enough evidence in many hundreds, if not thousands, of discrete small $\mathrm{N}$ case studies conducted over the last several decades. That productivity is indeed testament to our collective achievement and represents an investment in scholarly reflection.

But let me play devil's advocate and be somewhat provocative: I want to suggest that we have reached a point-save perhaps some intrepid souls-where few of us seem to be generating new ideas or conceptions of how to inform ourselves about new technologies. I want to suggest that each new study whose theoretical framework is founded on the philosophies of technological determinism and constructivism and concepts of co-evolution, co-constitution, and mutual shaping does not seem to add-let me be bold and say "any longer"-theoretically or empirically to understandings or our knowledge base. Yes, the core concepts remain critically important, but I also think we need to move beyond the point where journals like one I recently reviewed devote an entire issue to "gauging and debunking the effects of ICTs" (Mesch \& Zhao, 2010). I also think that an over-abundance of single-case analyses limits our ability to develop a coherent knowledge base.

\footnotetext{
${ }^{4}$ See, for example, Bilton, 2010; Bimber et al., 2005, 2009; Carr, 2008; Carlson, 2010; Clifford, 2010; Connolly, 2010; The Editors, 2010; Giridharadas, 2010; Holland, 2010; Johnson, 2010; Madden \& Rainie, 2010; Miller, 2010; Parker-Pope, 2010; Pinker, 2010; Richtel, 2010; Robbin, 2010; Scelfo, 2010; Singer, 2010; Smith, 2010; Sturken et al., 2004; Vandam, 2010; Wang \& Wellman, 2010; Winerip, 2010; Is technology unhinging our brains?, 2010.
} 
Please do not misunderstand me. I am not saying that there is not a proliferation of theoretical frameworks in use, or that these core concepts should be set aside, or that we should cease carrying out case studies.

\section{A Way Out}

Instead, I want to ask: Might it be fruitful to supplement our scholarly thinking regarding the status of new technologies and systematically incorporate other perspectives and theoretical frameworks and apply different empirical approaches as a foundation for our work in understanding information and communication technologies. Should we not be making use of a broader range of theoretical possibilities? Specifically I am thinking of ones that have received far less explicit attention, although they are nowhere "new", have been an implicit foundation for some of the scholarly work, and are stimulating and worthy of reflection? I am thinking of Karl Weick's (1990) suggestion regarding how to understand the new technologies and their impacts and the need to supplement existing concepts because the "features of the technologies necessitate a revision in the concepts we use to understand their place in organized life" (pp. 1-2).

One of my mentors, now deceased, Robert Alford (1998) believed that we needed to be multitheoretical in order to make advances in understanding the hard problems of our time. He encouraged us to work at transdisciplinary boundaries, to incorporate multiple theoretical frameworks and methodologies, to be grounded in the empirical world, and to move constantly between the evidence (data) and theory. Alford wanted us to be brave, recognizing that "the current configurations of power and resources in the field make it difficult to combine different paradigms of inquiry, although - paradoxically - outstanding works that achieve such combinations are sometimes rewarded with the highest prizes of the discipline" (p. 121). He argued that

multiple paradigms of inquiry must remain legitimate in social inquiry. The tensions among them need be neither dissolved nor reified. Isolating them from each other is a loss to each, since one depends on and presupposes the others [...] Pay attention to multiple kinds of arguments. Don't confuse statistical summaries and reductions of the data with causal inference. Do pay serious attention to the historical context of the data and the actual social processes and interactions that constitute the meaning of the data to human actors. (Alford, 1998, pp. 121-122).

Bimber and colleagues (2005) reinforce Alford's last prescription in their discussion about reconceptualizing collective action in the new media environment: "In our assessment, scholars should be asking not only whether examples of contemporary collective action fit the theoretical requirements for success, but also whether the theoretical ideal fits the rich array of collective actions now present in public life" (p. 366).

As my own thinking has evolved over the last few years, I look increasingly to conceptualizing technology adoption as a complex process and to considering notions of complexity, complex systems, and the relationship between the natural and social worlds. The philosophical foundation of my own thinking has always been: that it is useful to be unconstrained by disciplinary and speciality boundaries or dominant theoretical frameworks and methodologies; to rely on multiple theoretical paradigms, methodologies, and sources of evidence; to focus on macro- and micro-structures and processes; to take account of the context in which meaning is created and action taken; and to incorporate the contribution that history makes to (causal) explanation and meaning.

In the remaining time I would like to direct my remarks to theoretical frameworks or perspectives, concepts, and methodologies that I believe offer great promise for advancing our thinking as they relate to information and communication technologies. For this I draw on the thinking of five scholars whose work derives from significantly different ontological and epistemological stances and philosophic and intellectual traditions. However, I don't intend to emphasize these differences. Rather I want to focus on shared theoretical frameworks and core concepts that they have applied to studying information and communication technologies in the contemporary environment.

These scholars are Christian Fuchs and Wolfgang Hofkirchner of Austria, Gunilla Bradley of Sweden, Elinor Ostrom of the United States, and Bruce Bimber of the United States. I apologize in 
advance to these scholars for representing their ideas in highly simplified form and for ignoring the nuances that their thinking reflects; and for not emphasizing that all these scholars would immediately tell us that their scholarly work results from close collaboration with colleagues. But I do hope that I faithfully present some of their ideas.

The work of Fuchs and Hofkirchner is highly theoretical and critically evaluates many theories for their contribution to understanding a variety of dimensions of e-society as one part of the natural world that we inhabit. Hofkirchner is at work on developing an e-theory of the Information Society. Fuchs's orientation is towards employing Critical Systems Theory and has examined, for example, social movements and other participatory forms of action in the virtual world, globalization, cooperation, and the role of information and communication in a knowledge society, among a number of other aspects of the Information Society. Emancipation and trust are fundamental tenets and values for these two scholars.

Bruce Bimber has been an intellectual force in the study of new technologies for the last two decades, particularly for his work in questioning assumptions of a number of theories that have dominated political, social, and organizational behavior as they relate to the new technologies, for his outstanding empirical research, and for his assessments about the consequences of technology for human activity. His findings about the effects of the new information and communication technologies were initially unsettling but entered the mainstream of thinking about the relationship between technology, political organizations, and citizen engagement. He and his colleagues Andrew Flanagin and Cynthia Stohl reframe traditional collective action theory to account for collective action in the new media environment of self-organizing networks.

During Fall 2009, I conducted a fairly close reading of Gunilla Bradley's scholarly work on the psychosocial aspects of information and communication technologies (ICTs). Although much of her early work was focused on how computer and information technologies had consequences in the context of organizations, more recently one of the goals of her work has been to help us understand how our work and private lives have been transformed by computerization as she witnesses the dissolving of the boundaries of the private and public spheres (Bradley, 2006). The results of her research are testimony to how ICTs have consequences-both opportunities and risks-for work organizations, human communication, stress, allocation issues, knowledge transfer, and our global village (Bradley, 2000). Her empirical research has demonstrated that we live in a world where uncertainty, ambiguity, incomplete information, and unanticipated consequences brought on by the introduction of ICTs are the norm and produce various stresses and strains in response to constant adaptation and change (Bradley, 1989, 1993). In a word, we human beings are vulnerable but we adapt and our task is to create resilience in the face of this change.

What creates a link to Fuchs and Horkirchner's theoretical work is the heuristic model that she has developed for organizing her analysis at the individual, organisational, community, and societal levels and the interactions of the levels as subsystems and, as such, to represent hierarchy in nested systems. (More on this later.) The destination is "the Good Society." The route is possible through collective action, cooperation, and human values. Her work on the dissolving of boundaries of the public and private spheres, social capital, and a focus on communication provide two of several intellectual links to Bimber's work. And her thinking about reducing vulnerability and increasing reliance and about sustainability in a globalized world provides two of several connections to Ostrom. (You can get a sense of her thinking in the many call-for-paper topics for this conference.)

In November 2009, Elinor Ostrom of Indiana University received the Nobel Prize in Economics. ${ }^{5}$ Ostrom, whose work I was practically raised on, has spent her life "studying how people cooperate to manage a common resource" (Cho, 2010, p. 347). Although the foundation of her work has been Hardin's $(1968,1998)$ conception of the "Tragedy of the Commons", which "painted a disempowering, pessimistic vision of the human prospect", she and her students have demonstrated through

\footnotetext{
${ }^{5}$ This Nobel Prize for Economics was shared with Oliver Williamson, professor emeritus of the University of California. Williamson (1981) must be read for his contributions to understanding internal and external transactions costs experienced by different organizational governance structures. His work is relevant to my argument but is not addressed in my presentation.
} 
rigorous field and experimental empirical research that local and regional resources can be successfully managed (Ostrom et al., 1999, p. 278). However, success in managing a common-pool resource is not assured due to complexity, problematic sustainability, interactions, norms, interests, and governance structures, among the many factors.

Moreover, at a global scale, she and her colleagues write, the challenges are even greater to "develop effective approaches to common problems" (Ostrom et al., p. 278). These include the scaling-up problem, cultural diversity, complications of interlinked common pool resources, accelerating rates of change, the requirement of unanimous agreement as a collective-choice rule, and only one globe with which to experiment (pp. 281-282). Although Ostrom's work has focused on coupled human and natural systems, the underlying theories, concepts, and implications of the empirical findings are extensible to other contexts. Collective action, information, communication and technology are core aspects of her theoretical and empirical work on coupled social and ecological systems. And these aspects link Ostrom to Bradley's strongly empirical basis for her conclusions about the transformation of our daily and work lives by ICTs and to Bimber and his colleagues who reframe collective action in the new media environment.

\section{The Theoretical Frameworks}

\subsection{Systems and Complexity Thinking}

Burawoy (2003) tells us that "there is no way of seeing clearly without a theoretical lens" (p. 646) and that we must be "self-conscious and deliberate about the theories we employ" (p. 647); and so this is where I begin. ${ }^{6}$

The theoretical underpinnings of Fuchs and Hofkirchner's, Bradley's, and Ostrom's work lie in systems thinking, where the focus is on trying to pierce the "dynamic interactive complexity" and "incomprehensibility" of the new technologies (Weick, 1990, pp. 2, 4; see also Perrow, 1996). The foundations of their work also lie in collective action theory which Bimber and colleagues have recently reframed. Let me describe only most briefly, however, some of the concepts in these theories of systems and collective action and then turn to Bradley and Ostrom where I describe some of the core issues that they have articulated in their work.

Wikipedia provides an acceptable definition of the concept of a system: a "set of interacting or interdependent entities (elements, subsystems) forming an integrated whole."7 Systems have "structure, defined by parts and their composition; behavior, which involves inputs, processing and outputs of material, energy or information; interconnectivity (various parts have functional and structural relationships between each other; and by themselves functions or groups of functions" (Wikipedia, http://en.wikipedia.org/wiki/System). We associate our social and physical/natural systems with openness and complexity; the latter term "tends to be used to characterize something with many parts in intricate arrangement" (Wikipedia, http://en.wikipedia.org/wiki/Complexity). Society is a complex system (Fuchs, 2005, p. 10).

I adopt Fuchs's definition of complexity thinking which he identifies as "the recognition that there are non-linear relationships between causes and effects: one cause can have many different effects and one effect can be the combined result of many causes, small causes can have large effects and large causes small effects, i.e., effects are conditioned, but not determined by given structures, they have a certain degree of unpredictability and chance" (Fuchs, 2006, p. 111; 2003a, p. 112). ${ }^{8}$ Ostrom (2007, p. 15181) cites Holling (1998) and colleagues who add that these causes are not only "non-linear in nature, [but also] cross-scale in time and in space, and have an evolu-

\footnotetext{
${ }^{6}$ Let me emphasize the context for Burawoy's assertions is his "revisit" to the site where he conducted research that led to his thesis.

${ }^{7}$ Pumain $(2006$, p. 1) has noted the difficulty of defining a system, which is why I use the word "acceptable" for the definition.

${ }^{8}$ Pumain (2006, p. 1) notes that whereas "complex systems may have more or less simple components", they "always exhibit an overall behaviour that is difficult to analyse and predict from the list of components and the interactions between them".
} 
tionary character" (p. 352). Systems shift from "one state to another over time (temporal thresholds) and over space (spatial thresholds)" (Liu et al., 2007, p. 1514).

There are a number of properties associated with complex systems, among them: dynamic, selforganizing, evolution, persistence, sustainability, vulnerability, unpredictability, variation, resilience, adaption, hierarchy (nested), interaction and interdependency, emergence, feedback, control, information, technology, and communication (see Fuchs [2003b] and Fuchs and Obrist [2010] for a discussion). The concepts of communication and technology distinguish human systems and, according to Holling (2001), technology "amplifies the actions of humans so that they affect an astonishing range of scales...; and its evolution has progressively accelerated, changing the rules and context of the panarchies in the process" (pp. 397-398). ${ }^{9}$ (See fn 10 for a definition of "panarchy" by Holling and why he argues that it is a better term than "hierarchy.")

The concepts of self-organizing, emergence, technology, and communication are particularly relevant for the later discussion of the reframing of Collective Action Theory by Bimber and colleagues. Fuchs (2006), for example, notes that "the notion of social self-organization has political implications, it is closely related to categories such as participation, grass roots democracy, and co-operation" (p. 134).

Simon's (1973) conception of "hierarchy" as a property of the dynamics of complex systems is particularly important because it underlies Fuchs and Hofkirchner's and Bradley's conceptions of the Information Society and Ostrom's conception of coupled social and natural systems of common pool resources. ${ }^{10}$ "Hierarchy", Simon writes, "is associated with a very fundamental form of parsimony of interactions" (p. 15). Whether social or natural or physical, nearly all large systems can be very nearly decomposed into nested or hierarchical elements (pp. 7-8) which can be thought of as "levels" or "layers" in structural terms or "subsystems" in systems terms. Hierarchy is critical to large complex systems (p. 23). Through hierarchy a degree of independence creates greater stability in the system overall and "a measure of independence [of the subsystems or levels] to their special aspects of the environment without destroying their usefulness to the system" (pp. 23-24).

Now, think about the dynamics of the elements. There can be high or low degrees of interaction or interdependency in the processes inside each element but a certain degree of independence from levels above and below it. "The high frequency modes will control the internal interactions of the components of the lower level subsystems in the hierarchy, but will not be involved in the interactions among those subsystems (Simon, 1973, p. 10). It is, however, the "middle band of frequencies...that determine the observable dynamics of the system under study - the dynamics of interactions of the major subsystems" (p. 10).

Depending on the system in focus, "we can thus ignore the detailed structure or dynamics at the next level down and the very slow interactions at the next level up" (Simon, 1973, p. 11). Their loose or tightly horizontal or vertical coupling will determine the dynamics of independence and the extent to which the "inputs it requires and the outputs it produces are relevant for the larger aspects of system behavior" (p. 16). ${ }^{11}$ So, the relevance for systems is that we want to be able "to exploit

\footnotetext{
${ }^{9}$ Holling (2001) adds a third feature: foresight and intentionality (p. 401). Management must take surprise and unpredictability into account (p. 403). For more on this role of management and managing the unexpected through mindfulness, see Weick \& Sutcliffe (2007).

${ }^{10}$ Holling (2001) argues that "hierarchy" is an overused term and "burdened by the rigid-top-down nature of its common meaning" that he "decided to look for another term that would capture the adaptive and evolutionary nature of adaptive cycles that are nested one within each other across space and time scales" (p. 396). The "goal was to rationalize the interplay between change and persistence, between the predictable and the unpredictable" (p. 396). He settles on the term "panarchy" to represent "a hierarchy as a nested set of adaptive cycles" (p. 396). He wants to "transform hierarchies from fixed static structures to dynamic, adaptive entities whose levels are sensitive to small disturbances at the transition from growth to collapse and the transition from reorganization to rapid growth. At other times, the processes are stable and robust, constraining the lower levels and immune to the buzz of noise from small and faster processes" (p. 397). He goes on to explain that "there are two features that distinguish panarchical representation from traditional hierarchical ones: importance of the adaptive cycle and connections between levels" (p. 397).

${ }^{11}$ It is precisely this notion of coupling that is exceedingly relevant to those who are designing robust and resilient networks which have, increasingly, been recognized as fragile due to their interdependencies (see Vespignani, 2010). For more on the fragility of networked networks, see Keim (2010).
} 
loose horizontal coupling of subsystems that makes each subsystem independent of the exact timing of the operation of the others" (p. 18). Fuchs's (2006) discussion conceptualizes this property of the consequences of independence and interdependence in his work on the dialectical relationship between the global and the local in self-organizing systems.

Karl Weick (1990), it might be said, took a systems perspective with regard to technology when he argued some years ago that the new technologies are no longer "dominated by determinism. Instead, [we] operate in an environment whose important events are randomly occurring and unpredictable"; whose "uncertainties are permanent rather than transient"; whose "cause-effect relations are unclear"; and whose different technologies have "crucial properties with diverse consequences" (pp. 7, 8). Reliability is of paramount concern particularly because, increasingly, the new technologies "knit separate actors, transactions, and locations together into a continuous process" and interactive complexity makes them more prone to failure (pp. 12-13). Weick also notes another critical change induced by the new technologies that concerns abstract events (pp. 14-17):

More and more of the work associated with new technologies has disappeared into machines, which means that managers and operators experience increased cognitive demands for inference, imagination, integration, problem solving, and mental maps to monitor and understand what is going on out of sight (p. 14).

A colleague of Ostrom's Alessandro Vespignani (2010) makes concrete systems thinking, the consequences of coupling described by Simon, and Weick's contention that the new technologies are not dominated by determinism. Vespignani describes how interconnected networks form an "intricate web of critical infrastructure systems" (p. 984) that are complex systems "for which it is generally impossible to abstract the global behaviour from the analysis of single components, especially under conditions such as failures and disasters" (p. 984). Why are these networks fragile and vulnerable, Vespignani asks. It is due

to the large number of interdependent and different infrastructure types which include: physical interdependency when energy, material or people flow from one infrastructure to another; cyber interdependency when information is transmitted or exchanged; geographical interdependency such as the close spatial proximity of the elements of the infrastructure; logical interdependency such as financial dependence, political coordination and so on. (Vespignani, 2010, p. 984)

As you know, there is much more to systems thinking than I have indicated here. However, I wanted to highlight some of the key conceptual underpinnings that are relevant in thinking about a future research agenda for studying a variety of aspects of the Information Society.

\subsection{A Reframed (Reconceptualized) Collective Action Theory}

Two articles and a book chapter by Bruce Bimber and his colleagues Andrew Flanagin and Cynthia Stohl assess Mancur Olsen's (1965) theory of collective action for its relevance to conditions in the contemporary new media environment of advanced information and communication technologies (Bimber et al., 2005; Flanagin et al., 2006; Bimber et al., 2009). They argue that "many new kinds of collective actions are not well explained by existing collective action theory" (Flanagin et al., 2006, p. 30). They "reframe collective action as a set of communication processes involving the crossing of boundaries between private and public life that reflects how information and communication technologies have altered the formal organization's role in collective action " (Bimber et al., 2005, p. 367).

Collective action theory addresses three principal problems: information, communication, and cooperation. Two principal functional requirements of Olsen's theory are participation in "pursuit of the some collective [public] good" and the role of formal organizations (Bimber et al., 2005, p. $367) .^{12}$ Two of the "largest obstacles" addressed by traditional collective action theory are "free riding" and the need for formal organizations to overcome it (p. 369). People need to be motivated

\footnotetext{
${ }^{12}$ They consider databases of information and communications to be (less tangible) collective goods (p. 367).
} 
to participate and stay involved over long-periods of time; for this, information, communication, and close personal contact with each other (cooperation) are required. Their efforts need to be coordinated and, as such, collective action requires some sort of formal organization to solve this mobilization and coordination problem.

Bimber and colleagues (2005) find, however, instances of collective action that rely on ICTs that "appear to depart from some of the expectations of traditional theory, especially where discrete free-riding decisions and the role of organizations are concerned" (p. 369). ${ }^{13}$ ICTs make possible "communal information" at very low cost and "available by largely uncoordinated efforts", thus "creating what amounts to a second-order communality that makes the free-riding logic of collective action theories increasingly problematic" (p. 372). They point out that "individuals can now contribute to information repositories at low or only partial knowledge of other participants or contributors and without a clear intention or knowledge of contributing to communal information with public goods properties" (p. 372).

In traditional collective action theory, the role of organizations is essential for solving information, communication, and coordination problems (Bimber et al., 2005, p. 368). The new media technologies have, however, contributed to modifying the role of formal organizations. Now, "formal organizations, flexible decentralized organizations, networks, and even individuals [can] communicate and coordinate with others in ways that until recently were feasible almost exclusively for formal organizations" (p. 375). Moreover, in the past, formal organizations have had clearly demarcated external boundaries and clear lines of authority; but now "new types of cooperative endeavors and organizational structures" have evolved and redefined commitment requirements, cooperation, coordination (p. 376), for example, and "exhibit more fluidity and flexibility" (p. 376). Self-organizing networks solve the information problem "foreign to most formalized structures", which is "identifying people proximate to a location" (pp. 376-377).

Bimber (2005) and colleagues confirm that the "basic informational, communication, and coordination functions" identified by traditional collective action theory remain "requisite for the production of public goods" (p. 377). However, "new forms of collective action sharpen our view of these functions while disconfirming the theoretical expectation that formal organization is required to accomplish them" (p. 377)

This leads them to develop a model that reframes traditional collective action theory as a subclass of what they call the "collective action space." Their model "link[s] all the features of collective action" in the context of a new media environment "and the "more traditional constructs of freeriding and formal organization" (Bimber et al., 2005, p. 377). To take account of the evolution in collective action, they focus on the transition or boundary crossing from "a private domain of interest and action to a public one" (p. 377). That is, collective action takes place "when that boundary is crossed by two or more people in conjunction with a public good" (p. 377).

Boundary-crossing phenomena lie at the heart of new forms of technology-based collective action and "they also form the general class of which the traditional free-riding decision is one special, albeit very important, subset" (Bimber et al., 2005, p. 377). They argue that one of the effects of ICTs is "precisely to make boundaries between private and public domains porous and easily crossed" (p. 378). These technologies "help people develop collective identities and identify a common complaint or concern, and this enhances the public expression of new kinds of private interests" (p. 379).

The new technologies do not, however, eliminate the role of organizations, that is, they do not discard Olsen's requirement that collective action requires a formal organization. What Bimber, Flanagin and Stohl offer us is a proposal for collective action "that distinguishes organizations by the ways in which personal relations and activities are enacted" (Flanagin et al., 2006, p. 30).

Consequently, these scholars reframe the two dimensions of collective action, interaction and engagement. Instead of a binary conception of these two dimensions of Olson's (1965) traditional

\footnotetext{
${ }^{13}$ For example, protests against the World Trade Organization that took place in Seattle in 1999 and more recently in Italy, the International Transport Workers Federation campaign against the German tire maker Continental AG in 1999, the global anti-Iraq war protests in 2003, the International Campaign to End Landmines, among a number of worldwide protests.
} 
collective action theory, Bimber and colleagues propose that "collective actions exhibit variation" (Flanagin et al., 2006, p. 33). Thus, the mode of interaction "ranges from personal to impersonal and the mode of engagement ranges from entrepreneurial to institutional among participants in collective action efforts" (p. 33).

The horizontal axis displays the continuum of the interaction dimension that varies from the personal to the impersonal. Personal interaction "typically embodies mutual trust, shared norms, and close identification" which "facilitates boundary-crossing between the private and public realms" ( $p$. 34). Impersonal interaction "emphasizes the expression or pursuit of interests and concerns, and involves no personal, direct interaction with known others" who "remain largely unknown to each other in spite of their shared affiliation" (p. 34).

The new information and communication technologies also introduce variation in the organizational forms in which individuals interact in groups, There is a greater range of organizational forms and "roles in space and time" (Flanagin et al., 2006, p. 36); "form is flexible and may be adapted to fit context" (p. 39). Whereas Olson's theory focused on the formal characteristics of organizations, they suggest that it is more useful "not to distinguish organizations by their formal or informal characteristics...but rather by the ways in which personal relations and activities are enacted" (p. 38). Flanagin (2006) and colleagues continue:

Network-based collective action groups may exhibit many of the classic characteristics of network forms and comparatively few of those associated with bureaucracy. In such cases, fixed leadership and stable internal roles are less important, as are accumulated materials resources. Boundaries are defined by communication patterns rather than by flows of material resources and comparatively less effort is directed at protection and maintenance of the network as a structure over time. (Flanagin, 2006, pp. 36-37).

Accordingly, the vertical axis describes the continuum of mode of engagement and "represents the degree to which participants' individual agendas may be enacted within the group context" and "ranges from entrepreneurial to institutional" (Flanagin et al., 2006, p. 36). In the entrepreneurial engagement mode, "self-organizing mechanisms predominate" and "bureaucratic mechanisms of coordination and control are minimal" (p. 37). In contrast, the institutional engagement mode exhibits "a patterned set of normative rules of engagement, and practices...expected to be followed by all participants [and] individuals are embedded in a larger system that defines and controls opportunities for engagement" (p. 37). "Organizational hierarchy plays a key role [to influence] the shape and forms of engagement [and also serves] to reduce volatility" (p. 37).

I won't go into any more detail, but it is well worth taking the time to read the stimulating argument for revising traditional collective action theory made by Bimber, Flanagin, and Stohl. Also very useful is how they make connections to a number of theories. They link, for example, social capital theory to civic engagement theories, including interest group mobilization and social movements, theories of interaction, and theories of organizing and organization (Flanagin et al., 2006; Bimber et al., 2009).

\subsection{Convergence of Computer, Information, and Communication Technologies and Its Impli- cations}

Gunilla Bradley's work over more than forty years illustrates the core aspects of dynamic systems, a panarchy of nested subsystems, interdependency and interaction, communication, and changes induced by the new technologies that Weick described. She found that events were unpredictable, there were diverse consequences for different technologies, and there were cognitive demands on us human beings for understanding what is happening in our life worlds of public, civic, and private spheres and in a world that is undergoing historical change. Note here the nested subsystems and the interdependencies and interaction as illustrated in her theoretical model.

My intention here is not to dissect her theoretical model but rather to highlight a few of its salient aspects that reinforce the importance of theory, context, and history and the role that empirical 
work contributes for developing, evaluating, and extending theory, thus providing us with reflections on directions for future research.

The nature of the communicative act has been a central focus of Bradley's work in the organizational setting. As Maines (1977) wrote many years ago, "Through communication processes, people transform themselves and their environment and then respond to those transformations" ( $p$. 242). Bradley (1989) was to observe first-hand that how people communicated in their work lives was not independent of the introduction of new technologies in the work place. Rather, communication processes intersected with technological changes that were to have physical and psychological consequences. Technologies-in-use intervened in, mediated, and structured social and interpersonal interactions and work life in terms of the psychosocial work environment.

Bradley's (1993) long trajectory of research also permitted her to observe that (different) technologies differed in their effects: they "offer[ed] different conditions for the structure of organizations and the psychosocial environment" (p. 482). The evolution of technology was itself a significant variable; change or time mattered because we did not study a static system. As Bradley (2000) argued some years ago, change is continuous, affecting organizations and their contexts and structures, work roles and processes, and the appearance and disappearance of technology. Moreover, along with Bimber and colleagues, Bradley noted that technologies were altering the boundaries of the private and public spheres, dissolving what was once uniquely the site of stresses, that is, the work place, and incorporating them into home and private life.

What is our future as a collectivity? Bradley asks. Joining Fuchs and Horkirchner, Bradley (1989) asks us to think about the life conditions that we want, the characteristics of a good work environment and technologies that help us attain our goals, and the properties of our social structures, norms, and values systems that promote a positive climate for a society and a global world that have been transformed by computerization (pp. 18-19). We get to choose, she says. Committed to attaining a positive society and an interdependent global world through empirically based theory join her to Elinor Ostrom and her colleagues.

\subsection{Coupled Social and Ecological Systems}

Ostrom (2007) began a recent article in the Proceedings of the National Academy of Sciences by telling us that it is "presumptuous" to think that "scholars can make simple, predictive models of social-ecological systems (SESs) and deduce universal solutions, panaceas, to problems of overuse or destruction of resources" (p. 15181). She admonishes us to "stop striving for simple answers to solve complex problems" (p. 15181). Liu (2007) and his colleagues point out that when complexity is not well understood, "people may be surprised at the outcomes of human-nature coupling" ( $p$. 1514).

What Ostrom and her colleagues bring to bear is an understanding that the complex "dynamics of human-nature systems are influenced by many factors, including government policies and contextual factors in which local processes are shaped by larger-scale and ultimately global-scale processes" (Liu et al., 2007, p. 1514). Both markets and governance make decisions that have consequences for people and ecosystems (p. 1514). Furthermore, there are "legacy effects" of "prior human-nature couplings on later conditions" and the impacts of these couplings "may not be immediately observable or predictable" due to "time lags" (p. 1515). These "coupled systems change over time" and, Liu and colleagues note, "temporal changes take place not only inside a coupled system, but also across the boundaries" (Liu et al., 2007, p. 1516). This complexity of a dynamic nested interactive and interdependent complex system is represented in a figure that describes the core subsystems in a framework for analyzing social-ecological systems.

The properties of resilience ${ }^{14}$ and heterogeneity (variation) are salient issues for complex coupled systems. Liu (2007) and colleagues note that "Coupled systems have different degrees of resilience....and resilience can be affected by many factors" (p. 1515). Once again, as Bimber and colleagues observed in a different context, variation is important: "Human-nature couplings vary

\footnotetext{
${ }^{14}$ And its converse, vulnerability. See Adgar (2006) on vulnerability. See Folke (2006) on resilience.
} 
across time, space, and organizational units" (p. 1515). We are still "grappling with several key science issues, particularly related to aspects of how these complex transformations take place and interact at varying scales including local, regional and global levels", writes Vogel (2006, p. 25). (Fuchs (2006) devotes extensive space to the dialectics of globalization and localization, I should note.)

\subsection{Moving Forward Towards a Research Agenda}

How do we move forward, ask Ostrom and her colleagues? Much of what we know to date derives from discrete case studies; but these limit the extent of generalizing. What is needed is a coherent "interdisciplinary research program that integrates ecological and social sciences to study coupled human and natural systems"; it is necessary to "explicitly address complex interactions and feedback between human and natural systems"(Liu et al., 2007, p. 1513). Ostrom (2009) writes that "understanding a complex whole requires knowledge about specific variables and how their component parts are related" (p. 420).

This means addressing both the components and their connections, "measuring the ecological variables and human variables and also the variables that link natural and human components" (Liu, 2007, p. 1513). This means site-specific studies but also "coordinated long-term comparative projects across multiple sites to capture a full spectrum of variations" $p$. 1516). This means that at the same time that we focus on interactions within a system, we must also focus on the interactions across systems (p. 1516). This means, Ostrom (2009) argues, a framework that provides a "common set of potentially relevant variables and their subcomponents to use in the design of data collection instruments, the conduct of fieldwork, and the analysis of findings about the sustainability of complex SES" (p. 420).

This means "integrating various tools and techniques from different disciplines" that include "data collection, management, analysis, modeling, and integration" (Liu et al., 2007, p. 1513). This means not only qualitative data, but also quantitative data, experimental studies as well as surveys and field work. And this means that our research studies must be "simultaneously context-specific and longitudinal over periods of time long enough to elucidate temporal dynamics" (p. 1513).

Another aspect of our understanding about managing our collective resources also needs to be addressed and is implicit in the discussion about governance. Conflict. Policy is contested because the stakeholders have different assumptions, knowledge, and understandings. As Adams (2003) and colleagues point out with regard to common pool resources, stakeholders/actors "tend to ignore the fact that the assumptions, knowledge, and understandings that underlie the definition of resource problems are frequently uncertain and contested" (p. 1915). "Yet", as they contend, "the role of problem definition is rarely scrutinized" (p. 1915). Thus, in addition to making explicit components of systems, interactions and interdependencies, and measurements, we must work for transparency in the positions of the stakeholders (p. 1916). Collective management of our resources requires collaboration, and collaboration requires the development of social bonds and norms. Trust is at the heart of this. As Petty (2003) writes, trust is the "lubricant" of cooperation ( $p$. 1913). And it is this norm that also lies at the heart of both Bradley's and Ostrom's optimistic view of a "good society".

Without going into further detail, I recommend for stimulating reading an article by Young (2006) and colleagues on an agenda for scientific research that addresses the globalization of socioecological systems. I also recommend another stimulating article, one by Agrawal (2001) that is both a critique of the flawed methodologies and "relative merits of statistical, comparative, and case study approaches" that have dominated research on the commons and his "plea" for "careful research design and sample selection, construction of causal mechanisms, and a shift toward comparative and statistical rather than single case studies" (p. 1649). It may appear that analysis of the commons and common pool resources are far from relevant to our study of new technologies and the information society or social informatics. However, I want to assure you that the proposals made by these scholars are very relevant to our own research agendas. 
Theories of complex systems and collective action theories are not new. In fact, they are the foundation of a great deal of social, political, and communication theory, for example, and our empirical research. Yet, at the same time that these theories constitute the foundation of so much of our thought, they remain implicit and taken-for-granted. I believe that by beginning with the concept of complexity and making it explicit, we may collectively make progress in theory development, methodologies, and empirical work in our study of information and communication technologies.

\section{Concluding Remarks}

The origins of my talk are diverse. But looking back at my own intellectual trajectory, I find that my interest in "complexity" is long-standing. And in terms of my commenting on it at an earlier conference, I found the following words that I made in end-of-conference remarks at an IFIP's 2006 HCC7 conference in Maribor, Slovenia, in honor of Rob Kling, where I said:

I would like to urge a greater recognition of the dynamics of systems, contingency, and unpredictability. It would be useful to attend more explicitly to concepts of complexity, chaos, and disorder...We need to move from our expectation of linear processes and to examine the interactive, interdependent, and recursive nature of activities and events [...] We need to think more deeply about multiple levels of analysis and to integrate the social psychological, psychological, and cognitive along with institutional and other perspectives [...] We humans live in physical and temporal space. I would like to see the integration of the "e-" (as in "electronic" or virtual) with other lived spaces...

At the time I prepared the abstract for this address, I was more than three-quarters through my course in Organizational Informatics, which is always revelatory no matter how many times I have taught it because we spend much of the time studying many aspects of information and communication technologies in the context of complex organizations; and the daily press also keeps us rather busy with concrete, empirical illustrations of our readings. In this course, the phenomena of complexity, systems, tight and loose coupling, reliability, adaptation and change, unanticipated consequences, ambiguity and uncertainty, sense-making, mindfulness, and resilience are organizing concepts at multiple levels of analysis.

Additionally, two catastrophic events took place that encouraged me to pursue the central arguments that I make in this talk. On January 12, 2010, a 7.0 magnitude earthquake devastated Haiti and left the entire country in ruins. Then, on April 20th, the world learned of the explosion on a British Petroleum oil rig in the Gulf of Mexico that threatens human and natural systems and may possibly lead to wholesale destruction of coastal waters and the way of life for many people. This oil rig explosion not only has first-order effects but will have second-, and third-order effects and longterm consequences, not only for millions of people within the region but far removed from the site of the ruptured oil pipe. ${ }^{15}$

What we saw both in the Haiti and in the Gulf oil rig explosion was a worldwide mobilization through the Internet of people who organized many different types of services; multiple technologies were employed to move people and equipment to help the people of Haiti. We have also seen a worldwide mobilization through the Internet to gather ideas and assistance for the Gulf region. Yet, the technologies that were employed to mobilize networks for Haiti and the Gulf will not solve what are intractable problems of enormous complexity. ${ }^{16}$

Still, these two events were to reinforce my thinking about the theoretical perspectives and contributions of these five scholars Christian Fuchs, Wolfgang Hofkirchner, Gunilla Bradley, Bruce Bimber, and Elinor Ostrom. The connections of these five scholars are on the face of it seemingly unlikely. Yet, I saw them and wanted to share them, particularly for what they offer in terms of a future agenda for theory and methodological development and for empirical research on ICTs, the information society, and the achieving of a "Good Society." These scholars share a common goal in

\footnotetext{
${ }^{15}$ See Gillis \& Kaufman (2010) and Saulny (2010).

${ }^{16}$ See Sontag (2010) for a description of Haiti six months after the earthquake.
} 
their respective focus on the complexity of systems and, specifically, to a lifetime of studying the coupling of technological systems and social and natural systems, with the goals of improving the quality of life in community, local, regional, and international arenas.

Their connections rest not only on intellectual interests, however, but also on their commitment to creating psychologically and socially resilient human beings through robust theory, method, and empirical data. And, further, in the connection of their scholarly work to public policy. It is a conception of "the commons" that we all share, their stake in its sustainability and to collective action and cooperation.

Moreover, all five scholars are connected in their commitment to interdisciplinary research; to a generosity of spirit with regard to the credit they give to others; their dedication to and mentoring of their students; to their support for colleagues; to their commitment to building intellectual capacity through collective scholarship to tackle the problems that they have been committed to solving; and to their optimism about the human condition.

This is also our collective commitment.

Thank you very much.

\section{References}

Adams, W. M., Brockington, D., Dyson, J., \& Vira, B. (2003). Managing Tragedies. Understanding Conflict Over Common Pool Resources. Science, 302, 1915-1916.

Adger, W. N. (2006). Vulnerability. Global Environmental Change, 16, 268-281.

Agrawal, A. (2001). Common Property Institutions and Sustainable Governance of Resources. World Development, 29(10), 649-1672.

Agre, P. E. (2002). Real-Time Politics. The Internet and the Political Process. The Information Society, 18(5), 311-331.

Alford, R. R. (1998). The Craft of Inquiry. Theories, Methods, Evidence. New York: Oxford University Press.

Bellamy, C. \& Taylor, J. A. (1998). Governing in the Information Age. Buckingham: Open University Press.

Bijker, W. E. \& Law, J. (Eds.). (1992). Shaping Technology/Building Society. Studies in Sociotechnical Change. Cambridge, London: MIT Press.

Bilton, N. (2010, June, 11). The Defense of Computers, the Internet and Our Brains. New York Times. Retrieved June 10, 2010, from http://bits.blogs.nytimes.com/2010/06/11/in-defense-of-computers-the-internet-and-our-brains

Bimber, B. (1990). Karl Marx and the Three Faces of Technological Determinism. Social Studies of Science, 20(1), 333-381.

Bimber, B. (1998). The Internet and Political Transformation. Populism, Community, and Accelerated Pluralism. Polity, 31(1), 133-160.

Bimber, B. (1999). The Internet and Citizen Communication with Government. Does the Medium Matter? Political Communication, 16(4), 409-428.

Bimber, B. (2000). The Study of Information Technology and Civic Engagement. Political Communication, 17(4), 329-333.

Bimber, B. (2001). Information and Political Engagement in America. The Search for Effects of Information Technology. Political Research Quarterly, 54, 53-68.

Bimber, B., Flanagin, A. J., \& Stohl, C. (2005). Reconceptualizing Collective Action in the New Media Environment. Communication Theory, 12(5), 365-388.

Bimber, B., Stohl, C., \& Flanagin, A. J. (2009). Technological Change and the Shifting Nature of the Political Organization. In A. Chadwick, A. \& P. N. Howard (Eds.) Routledge Handbook of Internet Politics (pp. 72-85). London: Routledge.

Bradley, G. (1989). Computers and the Psychosocial Work Environment. Translated from the Swedish by Struan Robertson. London: Taylor \& Francis.

Bradley, G. (1993). What Happens to the Work Organization? In W. S. Marras, W. Karwowski, J. L. Smith, \& L. Pacholski (Eds.), Proceedings of the International Ergonomics Association World Conference on the Ergonomics of Manual Work, June 14-17, 1993, Warsaw, Poland. London, Washington DC: Taylor \& Francis.

Bradley, G. (2000). The Information and Communication Society. How People Will Live and Work in the New Millennium. Ergonomics, 43(7), 844-857.

Bradley, G. (2006). Social and Community Informatics. Humans on the Net. London: Routledge.

Bradley, G. (2010). The Convergence Theory on ICT, Society, and Human Beings - Towards the Good ICT Society. In A. Mirijamdotter \& D. M. Haftor (Eds.), Information and Communication Technologies, Society and Human Beings. Theory and Framework. Honouring Professor Gunilla Bradley. IGI Global Publishers (in press).

Burawoy, M. (2003). Revisits. An Outline of a Theory of Reflexive Ethnography. American Sociological Review, 68, 645-679. 
Carlson, B. F. (2010). Nicholas Carr on the 'Superficial' Webby Mind. Theatlantic.com, June. Retrieved June 7, 2010, from http://www.theatlantic.com/culture/archive/2010/06/nicolas-carr-on-the-superficial-webby-mind/57610

Carr, N. (2008). Is Google Making us Stupid? What the Internet is Doing to Our Brains. Theatlantic.com, July. Retrieved June 7, 2010, from http://www.theatlantic.com/magazine/archive/2008/07/is-google-making-us-stupid/6868

Cho, A. (2010). Laureates Analyzed Economics Outside Markets. Science, 326, 347.

Clifford, S. (2010, April 8). Teaching About Web Includes Troublesome Parts. New York Times. Retrieved April 8, 2010, from http://www.nytimes.com/2010/04/09/education/09cyberkids.html

Connelly, M. (2010, June 6). More Americans Sense a Downside to an Always Plugged-In Existence. New York Times. Retrieved June 10, 2010, from http://www.nytimes.com/2010/06/07/technology/07brainpoll.html

Danziger, J. N., Dutton, W. H., Kling, R., \& Kraemer, K. L. (1982). Computers and Politics: High Technology in American Local Governments. New York: Columbia University Press.

Flanagin, A. J., Flanagin, C., \& Flanagin, J. (2010). Technical Code and the Social Construction of the Internet. New Media \& Society, 12(2), 179-196.

Flanagin, A. J., Stohl, C., \& Bimber, B. (2006). Modeling the Structure of Collective Action. Communication Monographs, 73(1), 29-54.

Folke, C. (2006). Resilience. The Emergence of a Perspective for Social-Ecological Systems Analyses. Global Environmental Change, 16, 253-267.

Fuchs, C. (2003a). Globalization and Self-Organization in the Knowledge-Based Society. TripleC, 1(2), 105-169.

Fuchs, C. (2003b). Co-Operation and Self-Organization. TripleC, 1(1), 1-52.

Fuchs, C. (2005). Knowledge and Society from the Perspective of the Unified Theory of Information (UTI) Approach. Salzburg, Austria: Center for Information and Communication Technologies \& Society. Retrieved June 20, 2010, from http://www.mdpi.org/fis2005

Fuchs, C. (2006). The self-organization of social movements. Systems Practice and Action Research, 19(1), 101-137.

Fuchs, C. (2007). Towards a dynamic theory of virtual communities. International Journal of Knowledge and Learning, 3(45), 372-403. The version cited in my remarks is a word document entitled "The Self-Organization of Virtual Communities" (undated). Retrieved June 20, 2010, from http://www.socialtext.net/data/workspaces/socialmediaberkeley/attachments/syllabus:20071205215728-019235/original/VirtualCultureCommunity_V2.doc

Fuchs, C. (2009). Some Theoretical Foundations of Critical Media Studies. Reflections on Karl Marx and the Media. International Journal of Communication, 3, 369-402.

Fuchs, C. \& Obrist, M. (2010). HCl and Society. Towards a Typology of Universal Design Principles. International Journal of Human-Computer Interaction, 26(6), 638-656.

Fuchs, C., Hofkirchner, W., \& Klauninger, B. (2001/2007). The Dialectic of Bottom-Up and Top-Down Emergence in Social Systems. In G. de Zeeuw, M. Vahl, \& E. Mennuti (Eds.), Problems of Individual Emergence, Proceedings of a Conference Held in Amsterdam, The Netherlands, 16-20 April, 2001. Published in Systemica, 14(1-6), 127-150. Retrieved June 20, 2010, from http://fuchs.icts.sbg.ac.at/knowledge_kybernetes.pdf

Gillis, J. \& Kaufman, L. (2010, July 19). After Oil Spills, Hidden Damage Can Last for Years. New York Times. Retrieved July 19, 2010, from http://www.nytimes.com/2010/07/18/science/earth/18enviro.html

Giridharadas, A. (2010, April 9). Where A Cellphone Is Still Cutting Edge. New York Times. Retrieved April 12, 2010, from http://www.nytimes.com/2010/04/11/weekinreview/11 giridharadas.html

Hardin, G. (1968). The Tragedy of the Commons. Science, 162, 1243-1248.

Hardin, G. (1998). Extensions of "the Tragedy of the Commons." Science, 280(5364), 682-683.

Hofkirchner, W. (1998). Emergence and the Logic of Explanation. An Argument for the Unity of Science. Acta Polytechnica Scandinavica. Mathematics, Computing and Management in Engineering Series, 91, 23-30. Cited in Fuchs (2006).

Holland, J. (2010, July 27). Online Bullies Pull Schools into the Fray. New York Times. Retrieved June 27, 2010, from http://www.nytimes.com/2010/06/28/style/28bully.html

Holling, C. S. (2001). Understanding the Complexity of Economic, Ecological, and Social Systems. Ecosystems, 4, 390-405.

Holling, C. S., Berkes, F., \& Folke, C. (1998). Science, Sustainability, and Resource Management. In F. Berkes \& C. Folke (Eds.), Linking Social and Ecological Systems (pp. 342-362). Cambridge: Cambridge University Press.

Is technology unhinging our brains? (Letters to the Editor). (2010, June 17). New York Times. Retrieved June 19, 2010, from http://www.nytimes.com/2010/06/18/opinion/l18pinker.html

Johnson, S. (2010, June 19). Unboxed. Yes, People Still Read, But Now It's Social. New York Times. Retrieved June 19, 2010, from http://www.nytimes.com/2010/06/20/business/20unbox.html

Keim, B. (2010, April 15). Networked Networks Are Prone to Epic Failure. wired.com. Retrieved April 16, 2010, from http://www.wired.com/wiredscience/2010/04/networked-networks/

Kling, R. (2000a). Learning About Information Technologies and Social Change. The Contribution of Social Informatics. The Information Society, 16(3), 217-232. 
Kling, R. (2000b). Social Informatics: A New Perspective on Social Research About Information and Communication Technologies. Prometheus, 18(3), 245-264.

Kling, R., McKim, G., Fortuna, J., \& King, A. (2000). Scientific Collaboratories As Socio-Technical Interaction Networks. A Theoretical Approach (Working Paper SCIT-5).

Liu, J., Doetz, T., Carpenter, S. R., Alberti, M., Folke, C., et al. (2007). Complexity of Coupled Human and Natural Systems. Science, 317, 1513-1516.

MacKenzie, D. \& Wajcman, J. (Eds.). (1999). The Social Shaping of Technology (2nd ed.). Buckingham: Open University Press.

Madden, M. \& Rainie, L. (2010). Adults and Cell Phone Distractions. Washington, DC: Pew Internet \& American Life Project. Retrieved June 20, 2010, from http://www.pewinternet.org/ /media//Files/Reports/2010/PIP_Cell_Distractions.pdf

Maines, D. R. (1977). Social Organization and Social Structure in Symbolic Interactionist Thought. Annual Review of Sociology, 3, 235-259.

Mason, P. (2010, April 22). Election Zeitgeist: Blackberry World Does Not Get Iphone World. Bbc.com. Retrieved April 26, 2010, from http://www.bbc.co.uk/blogs/newsnight/paulmason/2010/04/election_zeitgeist_blackberry.html

Mesch, G. S. \& Zhao, S. (2010). Gauging and Debunking the Effects of ICTs. Information, Communication \& Society, 13(4), 467-469.

Miller, C. C. (2010, March 24). Online Social Networks Bridge Gaps for Chronically III. New York Times. Retrieved March 24 , 2010, from http://www.nytimes.com/2010/03/25/technology/25disable.html

Norris, P. (2002). Revolution, What Revolution? The Internet and U.S. Elections, 1992-2000. In E. Kamarck \& J. Nye (Eds.), Governance.com: Democracy in the Information Age (pp. 59-80). Washington, DC: Brookings Institution.

Olson, M. (1965). The Logic of Collective Action. Cambridge, MA: Harvard University Press.

Ostrom, E. (2007). A Diagnostic Approach for Going Beyond Panaceas. Proceedings of the National Academy of Sciences, 104(39), 15181-15187. doi:10.10737/pnas.0702288104

Ostrom, E. (2009). General Framework for Analyzing Sustainability of Social-Ecological Systems. Science, 325, 419-422.

Ostrom, E., Burger, J., Field, C. B., Norgaard, R. B., \& Policansky, D. (1999). Revisiting the Commons. Local Lessons, Global Challenges. Science, 284, 278-282.

Parker-Pope, T. (2010, June 6). An Ugly Toll of Technology: Impatience and Forgetfulness. New York Times. Retrieved June 10, 2010, from http://www.nytimes.com/2010/06/07/technology/07brainside.html

Perrow, C. (1999). Normal Accidents: Living with High-Risk Technologies (Updated ed.). Princeton: Princeton University Press.

Petty, J. (2003). Social Capital and the Collective Management of Resources. Science, 302, 1912-1914.

Pinker, S. (2010, June 10). Mind over Mass Media. New York Times. Retrieved June 19, 2010, from http://www.nytimes.com/2010/06/11/opinion/11Pinker.html

Pumain, D. (2006). Introduction. In D. Pumain (Ed.), Hierarchy in Natural and Social Sciences (pp. 1-12). The Netherlands: Springer.

Richtel, M. (2010, June 6). Hooked on Gadgets, and Paying a Price. New York Times, 8 June. Retrieved June 6, 2010, from http://www.nytimes.com/2010/06/07/technology/07brain.html

Robbin, A. (2010). Multitasking. Some Consequences of the Convergence of Technologies in the Workplace. In A. Mirijamdotter \& D. M. Haftor (Eds.), Information and Communication Technologies, Society and Human Beings: Theory and Framework. Honouring Professor Gunilla Bradley. IGI Global Publishers (in press).

Robbin, A., Courtright, C., \& Davis, L. (2004). ICTs and Political Life. Annual Review of Information Science and Technology, 38, 411-462. Medford: Information Today.

Saulny, S. (2010, July 18). Cajuns on Gulf Worry That They May Have to Move Again. New York Times. Retrieved July 20, 2010, from http://www.nytimes.com/2010/07/19/us/19cajun.html

Scelfo, J. (2010, June 9). The Risks of Parenting While Plugged In. New York Times. Retrieved June 10, 2010, from http://www.nytimes.com/2010/06/10/garden/10childtech.html

Simon, H. A. (2006). The Organization of Complex Systems. In H. H. Pattee (Ed.), Hierarchy Theory. The Challenge of Complex Systems. New York: George Braziller.

Singer, N. (2010, May 28). When Patients Meet Online, Are There Side Effects? New York Times. Retrieved May 30, 2010, from http://www.nytimes.com/2010/05/30/business/30stream.html

Smith, A. (2010). Neighbors Online. Washington, DC: Pew Internet \& American Life Project. Retrieved June 9, 2010, from http://pewinternet.org/Reports/2010/Neighbors-Online.aspx

Sontag, D. (2010, July 11). In Haiti, the Displaced Are Left Clinging to the Edge. New York Times. Retrieved July 11, 2010, from http://www.nytimes.com/2010/07/11/world/americas/11haiti.html

Sturken, M. \& Tomas, D. (2004). Introduction: Technological Visions and the Rhetoric of the New. In M. Sturken, D. Thomas, \& S. J. Ball-Rokeach (Eds.), Technological Visions: The Hopes and Fears That Shape New Technologies (pp. 1-18). Philadelphia: Temple University Press. 
Sturken, M., Thomas, D., \& Ball-Rokeach, S. J. (Eds.). (2004). Technological Visions. The Hopes and Fears That Shape New Technologies. Philadelphia: Temple University Press.

The Editors. (2010, January 28). Wired Kids, Negligent Parents. New York Times. Retrieved January 29, 2010, from http://roomfordebate.blogs.nytimes.com/2010/01/28/wired-kids-negligent-parents/

Vandam, J. (2010, May 27). Brooklyn Developer Builds Following on Blog. New York Times. Retrieved May 30, 2010, from http://www.nytimes.com/2010/05/30/realestate/30condo.html

Vespignani, A. (2010, April 15). The Fragility of Interdependency. Nature, 464, 984-985.

Vogel, C. (2006). Foreword: Resilience, Vulnerability and Adaptation: A Cross-Cutting Theme of the International Human Dimensions Programme on Global Environmental Change. Global Environmental Change, 16, 25-26.

Wang, H. \& Wellman, B. (2010). Social Connectivity in America: Changes in Adult Friendship Network from 2002-2007. American Behavioral Scientist, 53(8), 1148-1169.

Weaver, D. A., Lively, E., \& Bimber, B. (2009). Searching for a Frame. News Media Tell the Story of Technological Progress, Risk, and Regulation. Science Communication, 31(2), 139-166.

Weick, K. E. (1990). Technology as Equivoque. In P. S. Goodman, L. S. Sproull, \& Associates (Eds.), Technology and Organizations (pp. 1-44). San Francisco: Jossey-Bass.

Weick, K. E. \& Sutcliffe, K. M. (2007). Managing the Unexpected. Resilient Performance in an Age of Uncertainty (2nd ed.). San Francisco: Jossey-Bass.

Williamson, O. E. (1981). The Economics of Organization. The Transaction Cost Approach. The American Journal of Sociology, 87(3), 548-577.

Wimmer, L. (2004). Sow's ears from Silk Purses: The Strange Alchemy of Technological Visionaries. In M. Sturken, D. Thomas, \& S. J. Ball-Rokeach (Eds.), Technological Visions. The Hopes and Fears That Shape New Technologies (pp. 34-47). Philadelphia: Temple University Press.

Winerip, M. (2010, January 17). On Vacation and Looking for Wi-Fi. New York Times. Retrieved January 16, 2010, from http://www.nytimes.com/2010/01/17/fashion/17genb.html

Young, O. R., Berkhout, F., Gallopin, G. C., et al. (2006). The Globalization of Socio-Ecological Systems: An Agenda for Scientific Research. Global Environmental Change, 16, 304.

\section{About the Author}

Alice Robbin

Alice Robbin teaches in the School of Library and Information Science at Indiana University Bloomington. Her research interests include social and organizational informatics, e-government, technology innovation, adoption, and diffusion, the digital divide and inequality; political communication; and public policy. She received her Ph.D. in political science (minor in sociology) from the University of Wisconsin-Madison and has taught at City University of New York, Long Island University, and Florida State University. She is currently working with her colleague Antoine Harfouche of the University of Tours and University of Paris Dauphine on the adoption of e-public services in Lebanon. 